\title{
Impact of Prescriptionauditing and Intervention of Infectious Diseases Specialist on The Use of Antimicrobials in Intensive Care Units
}

Ravena Melo Ribeiro da Silva ( $\square$ ravena_melo_@hotmail.com )

Federal University of Sergipe: Universidade Federal de Sergipe https://orcid.org/0000-0002-0923-7704 Ana Cláudia de Brito Câmara

Emergency Sergipe Hospital

Ellen Karla Chaves Vieira Koga

Emergency Sergipe Hospital

Iza Maria Fraga Lobo

Emergency Sergipe Hospital

Wellington Barros da Silva

Federal University of Sergipe: Universidade Federal de Sergipe

Research article

Keywords: Anti-Infective Agents, Antimicrobial Stewardship, Drug Resistance, Intensive Care Units

Posted Date: March 10th, 2021

DOI: https://doi.org/10.21203/rs.3.rs-296854/v1

License: (9) This work is licensed under a Creative Commons Attribution 4.0 International License.

Read Full License 


\section{Abstract}

Background: Antimicrobials are among the most prescribed drugs in ICUs, where the use of these drugs is approximately 10 times greater than that of other wards. Even so, it is observed that between 30 to $60 \%$ of antimicrobial prescriptions performed in these units are unnecessary or inadequate. Thus, surveillance of antimicrobial prescription is a first and essential step to identify potential overuse or misuse, which could be the target of interventions for antimicrobial administration.

Methods: This is an observational, analytical, and prospective study conducted in two adult intensive care units (ICU 1 = surgical and ICU 2 = clinic), with 27 beds each. The study period was divided into preintervention (January to June 2019) and post-intervention (July to December 2019).

Results: Overall, in the pre- and post-intervention period, $91.4 \%$ and $90.0 \%$, respectively, of patients received at least one antimicrobial agent. The most frequently prescribed antimicrobial classes were carbapenems (PRE $=26.0 \%$ vs POST $=24.9 \% ; p=0.245$ ) followed by glycopeptides (PRE $=21.0 \%$ vs POST $=18.6 \% ; p=0.056)$. Overall, there was a significant reduction in the duration of therapy (PRE $=727$ LOT / 1000pd vs POST $=680$ LOT / 1000pd; $p=0.028$ ). The highest rates regarding the time of use of antimicrobials were observed for carbapenems, followed by glycopeptides, with significant reductions in the time of exposure of glycopeptides and polymyxin B, and significant increases for penicillins, and tigecycline.

Conclusions: In general, the intervention of infectious diseases specialistsin intensive care units had a limited impact on the results evaluated. This may be due to the short period analyzed. Therefore, it is important to monitor the impact of these changes in the long term, drawing a more accurate assessment of the effectiveness of an intervention, with the implementation of active feedback.

\section{Background}

Intensive care units (ICUs) can be a critical area for the emergence and dissemination of microbial resistance because it is a complex population, with severe clinical conditions and associated comorbidities, in addition to vulnerability to the large number of invasive procedures, where rates of nosocomial infections vary from 5 to $30 \%$ [1].

In this scenario, antimicrobials are among the most prescribed drugs in ICUs, in which the use of these drugs is approximately 10 times greater than that of other wards [1-3]. Even so, it is observed that between 30 to $60 \%$ of antimicrobial prescriptions performed in these units are unnecessary or inadequate [4]. The excessive and long-term use of antimicrobials has led to an increase in the number of adverse events related to drugs, increased health care costs, and, mainly, exerted selective pressure, contributing to microbial resistance, threatening its therapeutic efficacy $[1,4,5-9]$. 
Monitoring the use of antimicrobials in hospitals has become an instrument of great interest and particular attention in recent years [5]. In ICUs, this monitoring has an even greater need, due to the patient's clinical condition, with higher rates of infections, especially nosocomial, high rates of resistance, and mortality [4]. Thus, surveillance of antimicrobial prescription is a first and essential step to identify potential overuse or misuse, which could be the target of interventions for antimicrobial administration [3].

The Management of Surveillance and Monitoring in Health Services and General Management of Technology in Health Services through the "National Guideline for the Development of a Management Program for the Use of Antimicrobials in Health Services" has proposed as process measures for the evaluation of the use of antimicrobials the Days of therapy (DOT) and Length of therapy (LOT) indicators [10]. That guideline describes DOT as the number of days a patient receives an antimicrobial agent, regardless of the dose. While the LOT is the number of days that the patient receives antimicrobial agents, regardless of the number of drugs. The DOT / LOT ratio reveals the combination of antimicrobial therapy or monotherapy, when the ratio is equal to 1 , monotherapy is identified, when greater than 1 , it is identified that a therapeutic combination was used.

There is no way to prove that initiatives for the rational use of antimicrobials are carried out if there is no data analysis, with these indicators help to understand, quantify and map how antimicrobials are used in hospital units. Also, in the ICUs, the use of the DOT and LOT indicators is more relevant when compared to the Defined Daily Dose (DDD), the most widely used metric, as it avoids problems related to dosage modifications [4]. After a bibliographic survey, carried out by the authors, in the PUBMED, LILACS, and SCIELO databases, there was a scarcity of studies involving the use of DOT and LOT metrics in the evaluation of the use of antimicrobials in Brazil. Given the above, this study aimed to assess the impact of daily audits, performed on medical prescriptions with antimicrobial therapies, and interventions performed by infectious diseases specialists, through the DOT and LOT indicators, in two intensive care units, in a tertiary care hospital in northeastern Brazil.

\section{Methods}

\section{Design and setting}

This is an observational, analytical, and prospective study conducted in two adult intensive care units (ICU 1 = surgical and ICU 2 = clinic), with 27 beds each. The study period was divided into pre-intervention (January to June 2019) and post-intervention (July to December 2019). The intervention phase took place in the first week of July when the unit's infectious diseases specialist had the initiative to audit the medical prescriptions that involved antimicrobial therapy.

\section{Inclusion and exclusion criteria}

The population of patients admitted to the units (including those who did not receive antimicrobials), between January 1 and December 31, 2019, was included, with analysis of antimicrobial agents 
administered intravenously or orally.

The exclusion criteria involved patients with a stay of fewer than 24 hours, and administration of antimicrobials by intramuscular, topical, ophthalmic, inhalation, antiviral, and antiretroviral routes.

\section{Data Source}

The review of prescriptions and data extraction were performed by the researcher pharmacists RMRS, using an electronic database created especially for this purpose. The data regarding the use of antimicrobials were obtained from the individual prescriptions of the patients and forms of requests for antimicrobials, under the responsibility of the hospital pharmacy.

Other data were extracted from the records of active search under the surveillance of hospital infections carried out by the Center for Epidemiology, Patient Safety, and Hospital Infection.

\section{Outcome measures}

Primary outcomes were represented by the percentage of patients using antimicrobials and type of antimicrobial prescribed, by class and agent, routes of administration, and diagnostic indications. Secondary outcomes included analyzes of pre- and post-intervention periods in the use of antimicrobials, expressed as DOT and LOT per 1000 patient days; the incidence of Methicillin-resistant Staphylococcus aureus (Methicillin ${ }^{\mathrm{R}}$ ), Vancomycin-resistant enterococci (Vancomycin ${ }^{\mathrm{R}}$ ), Carbapenem-resistant Pseudomonas aeruginosa (P. Carbapenem ${ }^{R}$ ), Carbapenem-resistant Acinetobacter baumannii (A. Carbapenem ${ }^{R}$ ), and Carbapenem-resistant Enterobacteriaceae (E. Carbapenem ${ }^{R}$ ); and the average length of stay in the units, and overall mortality.

Data entry and storage were performed in Microsoft Excel 2019 (Microsoft Corporation, Redmond, WA, USA), transferred for statistical analysis using Stata software version 15.1 (StataCorp, College Station, Texas, USA).

\section{Statistical analysis}

The variables were expressed as percentages, mean \pm standard deviation (SD), or median with interquartile range (IQR: 25-75 percentile). The normality of data distribution was verified and compared using Student's t test or Wilcoxon rank-sum tests, as appropriate. The level of statistical significance was set at 0.05 .

\section{Results}

During the study period, 981 patients were followed, 510 in ICU 1 and 471 in ICU 2, represented by 19,550 patient-days, with a median age of 54 years (IQR: 37-67) and 51 years (IQR: 33-65), respectively. Overall, in the pre- and post-intervention period, $91.4 \%$ and $90.0 \%$, respectively, of patients received at least one antimicrobial agent. Slight reductions, but not statistically significant, were observed both individually in the ICU and combined after the intervention. Intravenous administration was present in $97.9 \%$ of pre- 
intervention prescriptions and $97.5 \%$ post-intervention, with a reduction, although not significant, in the combined ICUs, linked to the reduction of this route in ICU 1 prescriptions (Table 1).

The most frequently prescribed antimicrobial classes, in the combined ICUs, were related to carbapenems $(\mathrm{PRE}=26.0 \%$ vs POST $=24.9 \% ; p=0.245)$ followed by glycopeptides $(\mathrm{PRE}=21.0 \%$ vs $\mathrm{POST}=18.6 \% ; p=$ 0.056). There was no statistically significant difference for any of the classes prescribed between the preand post-intervention periods. In the individual analysis of each ICU, after the interventions, there were significant increases in ICU 1, referring to the number of tigecycline prescriptions (PRE $=0 \%$ vs POST $=$ $1.4 \% ; p=0.043$ ) and azithromycin (PRE $=0.6 \%$ vs POST $=1.1 \% ; p=0.029$ ). In contrast, in ICU 2 , a notable increase was found for the prescription of penicillin (PRE $=2.2 \%$ vs POST $=4.5 \% ; p=0.041$ ) (Table 1$)$. 
Table 1

Distribution of antimicrobial use, per unit, 2019.

\begin{tabular}{|c|c|c|c|c|c|c|c|c|c|}
\hline \multirow[t]{3}{*}{ VARIABLES } & \multicolumn{9}{|c|}{ UNITS } \\
\hline & \multicolumn{3}{|c|}{ GLOBAL } & \multicolumn{3}{|l|}{ ICU 1} & \multicolumn{3}{|c|}{ ICU 2} \\
\hline & PRE & POST & $\begin{array}{l}\text { p- } \\
\text { value }\end{array}$ & PRE & POST & $\begin{array}{l}\mathrm{p}- \\
\text { value }\end{array}$ & PRE & POST & $\begin{array}{l}\mathrm{p}- \\
\text { value }\end{array}$ \\
\hline $\begin{array}{l}\text { Use of } \\
\text { antimicrobials (\%) }\end{array}$ & 91.4 & 90.0 & $\otimes 0.308$ & 91.5 & 89.8 & $\bowtie 0.297$ & 91.4 & 90.3 & $\llbracket 0.569$ \\
\hline Endovenous via & 97.9 & 97.5 & $凶 0.695$ & 98.7 & 97.5 & $\bowtie 0.099$ & 97.1 & 97.5 & $\llbracket 0.646$ \\
\hline \multicolumn{10}{|l|}{$\begin{array}{l}\text { Number Of } \\
\text { Prescriptions (\%) }\end{array}$} \\
\hline Carbapenems IV & 26.0 & 24.9 & $\otimes 0.245$ & 25.7 & 23.4 & $\bowtie 0.098$ & 26.2 & 26.5 & $\otimes 0.605$ \\
\hline Glycopeptides IV & 21.0 & 18.6 & $\otimes 0.056$ & 21.2 & 19.0 & $\bowtie 0.163$ & 20.8 & 18.3 & $\llbracket 0.192$ \\
\hline $\begin{array}{l}\text { Aminoglycosides } \\
\text { IV }\end{array}$ & 8.7 & 7.4 & $\otimes 0.157$ & 8.1 & 7.8 & $\bowtie 0.628$ & 9.2 & 6.9 & $\llbracket 0.130$ \\
\hline $\begin{array}{l}\text { Third-generation } \\
\text { cephalosporins IV }\end{array}$ & 7.0 & 8.3 & $\bowtie 0.187$ & 7.1 & 7.1 & $\llbracket 0.836$ & 6.9 & 9.8 & $\llbracket 0.177$ \\
\hline Cefepime IV & 6.5 & 7.0 & $₫ 0.415$ & 8.2 & 9.2 & $\llbracket 0.299$ & 4.9 & 4.4 & $\llbracket 0.771$ \\
\hline Polymyxin B IV & 7.3 & 6.0 & $\bowtie 0.275$ & 6.2 & 5.6 & $\bowtie 0.596$ & 8.3 & 6.5 & $\llbracket 0.261$ \\
\hline Antifungals IV/PO & 6.0 & 5.3 & $₫ 0.252$ & 6.3 & 5.4 & $\llbracket 0.611$ & 5.7 & 5.3 & $\llbracket 0.637$ \\
\hline $\begin{array}{l}\text { Clindamycin } \\
\text { IV/PO }\end{array}$ & 4.1 & 4.9 & $\otimes 0.560$ & 3.7 & 4.4 & $\llbracket 0.606$ & 4.5 & 5.4 & $\llbracket 0.601$ \\
\hline $\begin{array}{l}\text { Metronidazole } \\
\text { IV/PO }\end{array}$ & 3.4 & 4.4 & $₫ 0.497$ & 2.8 & 4.5 & $\llbracket 0.214$ & 4.0 & 4.3 & $\llbracket 0.819$ \\
\hline Penicillins ${ }^{1}$ IV/PO & 2.2 & 4.5 & $\bowtie 0.016$ & 2.3 & 4.4 & $\bowtie 0.080$ & 2.2 & 4.5 & $\llbracket 0.041^{\star}$ \\
\hline $\begin{array}{l}\text { First-generation } \\
\text { cephalosporins } \\
\text { IV/PO }\end{array}$ & 3.6 & 3.1 & $\otimes 0.464$ & 4.7 & 4.2 & $\llbracket 0.495$ & 2.4 & 1.8 & $\llbracket 0.251$ \\
\hline $\begin{array}{l}\text { Fluoroquinolones } \\
\text { IV/PO }\end{array}$ & 1.9 & 1.7 & $\bowtie 0.617$ & 1.9 & 1.2 & $\bowtie 0.400$ & 1.9 & 2.2 & $\llbracket 0.786$ \\
\hline $\begin{array}{l}\text { Co-trimoxazole } \\
\text { IV/PO }\end{array}$ & 1.3 & 1.4 & $\bowtie 0.803$ & 1.2 & 1.5 & $\bowtie 0.385$ & 1.4 & 1.3 & $\llbracket 0.820$ \\
\hline Tigecycline & 0.2 & 1.8 & $\bowtie 0.058$ & 0 & 1.4 & $\varangle 0.043 *$ & 0.3 & 2.2 & $\llbracket 0.075$ \\
\hline
\end{tabular}

Legends: ICU 1 = surgical; ICU = clinic. $\otimes$ Student's $t$ test, $\otimes$ Wilcoxon rank-sum tests, ${ }^{*} p$-value $<0.05$ 


\begin{tabular}{|c|c|c|c|c|c|c|c|c|c|}
\hline \multirow[t]{3}{*}{ VARIABLES } & \multicolumn{9}{|c|}{ UNITS } \\
\hline & \multicolumn{3}{|c|}{ GLOBAL } & \multicolumn{3}{|c|}{ ICU 1} & \multicolumn{3}{|l|}{ ICU 2} \\
\hline & PRE & POST & $\begin{array}{l}\text { p- } \\
\text { value }\end{array}$ & PRE & POST & $\begin{array}{l}\mathrm{p}- \\
\text { value }\end{array}$ & PRE & POST & $\begin{array}{l}\mathrm{p} \text { - } \\
\text { value }\end{array}$ \\
\hline $\begin{array}{l}\text { Azithromycin } \\
\text { IV/PO }\end{array}$ & 0.9 & 0.8 & $₫ 0.633$ & 0.6 & 1.1 & $\varangle 0.029 *$ & 1.2 & 0.5 & $\triangle 0.279$ \\
\hline
\end{tabular}

In the individual analysis of each ICU, after the interventions, there were significant increases in ICU 1 , referring to the number of tigecycline prescriptions (PRE $=0 \%$ vs POST $=1.4 \% ; p=0.043$ ) and azithromycin (PRE $=0.6 \%$ vs POST $=1.1 \% ; p=0.029)$. In contrast, in ICU 2, a notable increase was found for the prescription of penicillin (PRE $=2.2 \%$ vs POST $=4.5 \% ; p=0.041$ ) (Table 1 ).

Regarding the duration of therapy, although its reduction was not significant in the units in isolation, overall, this data was significant (PRE $=727$ LOT / 1000pd vs POST $=680$ LOT / 1000pd; $p=0.028$ ). Each patient received an average of $1.8 \pm 0.2$ antimicrobials during their stay in the units, with a significant reduction combined (PRE = 1.9 DOT / LOT vs POST $=1.7$ DOT / LOT; $p=0.046)$ linked to a reduction in ICU 2 (PRE = 1.9 DOT / LOT vs POST = 1.7 DOT / LOT; p = 0.007) (Table 2). 
Table 2

Antimicrobial use rates, per unit, 2019.

\begin{tabular}{|c|c|c|c|c|c|c|c|c|c|}
\hline \multirow[t]{3}{*}{ VARIABLES } & \multicolumn{9}{|c|}{ UNITS } \\
\hline & \multicolumn{3}{|c|}{ GLOBAL } & \multicolumn{3}{|l|}{ ICU 1} & \multicolumn{3}{|l|}{ ICU 2} \\
\hline & PRE & POST & $\begin{array}{l}\mathrm{p}- \\
\text { value }\end{array}$ & PRE & POST & $\begin{array}{l}\mathrm{p}- \\
\text { value }\end{array}$ & PRE & POST & $\begin{array}{l}\mathrm{p}- \\
\text { value }\end{array}$ \\
\hline LOT/1000pd & 727 & 680 & $\varangle 0.028 *$ & 726 & 684 & $凶 0.104$ & 728 & 677 & $\otimes 0.220$ \\
\hline DOT/LOT ratio & 1.9 & 1.7 & $\otimes 0.046 *$ & 1.8 & 1.8 & $\otimes 0.235$ & 1.9 & 1.7 & $\otimes 0.007 *$ \\
\hline \multicolumn{10}{|l|}{ DOT/1000pd } \\
\hline Carbapenems IV & 412 & 376 & $\otimes 0.117$ & 408 & 392 & $\bowtie 0.753$ & 416 & 361 & $\otimes 0.014 *$ \\
\hline Glycopeptides IV & 284 & 234 & $\otimes 0.014 *$ & 280 & 251 & $\bowtie 0.320$ & 289 & 216 & $\otimes 0.011^{*}$ \\
\hline $\begin{array}{l}\text { Aminoglycosides } \\
\text { IV }\end{array}$ & 124 & 103 & $\otimes 0.111$ & 124 & 109 & $\bowtie 0.226$ & 124 & 97 & $\otimes 0.249$ \\
\hline Polymyxin B & 121 & 88 & $\varangle 0.029 *$ & 100 & 85 & $\nabla 0.169$ & 141 & 92 & 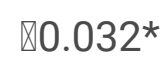 \\
\hline Antifungals IV/PO & 74 & 67 & $\triangle 0.516$ & 76 & 72 & $凶 0.831$ & 72 & 63 & $\otimes 0.541$ \\
\hline $\begin{array}{l}\text { Third-generation } \\
\text { cephalosporins IV }\end{array}$ & 59 & 73 & $\triangle 0.226$ & 54 & 62 & $凶 0.531$ & 65 & 83 & $\otimes 0.364$ \\
\hline Cefepime IV & 67 & 61 & $\otimes 0.647$ & 83 & 84 & $\bowtie 0.932$ & 51 & 37 & $\otimes 0.409$ \\
\hline Clindamycin IV & 39 & 42 & $₫ 0.843$ & 31 & 36 & $\bowtie 0.590$ & 48 & 47 & $\otimes 0.960$ \\
\hline Penicillins ${ }^{1}$ IV/PO & 25 & 45 & $₫ 0.009 *$ & 25 & 39 & $₫ 0.008^{*}$ & 26 & 51 & $₫ 0.041 *$ \\
\hline $\begin{array}{l}\text { Metronidazole } \\
\text { IV/PO }\end{array}$ & 39 & 31 & $₫ 0.315$ & 28 & 27 & $凶 0.895$ & 49 & 35 & $₫ 0.407$ \\
\hline $\begin{array}{l}\text { Co-trimoxazole } \\
\text { IV/PO }\end{array}$ & 20 & 18 & $\triangle 0.823$ & 11 & 19 & $\otimes 0.384$ & 29 & 18 & $\otimes 0.917$ \\
\hline $\begin{array}{l}\text { First-generation } \\
\text { cephalosporins } \\
\text { IV/PO }\end{array}$ & 19 & 15 & $\triangle 0.409$ & 27 & 22 & $₫ 0.645$ & 12 & 8 & $\otimes 0.262$ \\
\hline $\begin{array}{l}\text { Fluoroquinolones } \\
\text { IV/PO }\end{array}$ & 18 & 17 & $\otimes 0.917$ & 19 & 8 & $\bowtie 0.400$ & 16 & 26 & $\otimes 0.917$ \\
\hline Tigecycline & 3 & 27 & $\varangle 0.046^{\star}$ & 0 & 23 & $凶 0.043^{*}$ & 5 & 30 & $₫ 0.075$ \\
\hline $\begin{array}{l}\text { Azithromycin } \\
\text { IV/PO }\end{array}$ & 8 & 6 & $\otimes 0.325$ & 5 & 10 & $\bowtie 0.347$ & 11 & 3 & $₫ 0.223$ \\
\hline
\end{tabular}


Overall, the highest rates regarding the time of use of antimicrobials were observed for carbapenems, followed by glycopeptides, with significant reductions in the time of exposure of glycopeptides (PRE = 284 DOT / 1000pd vs POST = 234 DOT / 1000pd; $p=0.014)$ and polymyxin B (PRE = 121 DOT / 1000pd vs POST = 88 DOT / 1000pd; $p=0.029$ ), however significant increases were observed for penicillins (PRE $=25$ DOT $/ 1000 p d$ vs POST $=45$ DOT $/ 1000 p d ; p=0.009)$, and tigecycline (PRE = 3 DOT $/ 1000 p d$ vs POST $=27$ DOT $/ 1000 p d ; p=0.046)$. In the individual analysis of the units, ICU 1 , had a significant increase in the time of use of penicillins (PRE = 25 DOT / 1000pd vs POST = 39 DOT / 1000pd; $p=0.008$ ), and tigecycline (PRE = 0 DOT / 1000pd vs POST = 23 DOT / 1000pd; $p=0.043)$. In ICU 2, there was a shorter time of use of carbapenems (PRE = 416 DOT / 1000pd vs POST = 361 DOT / 1000pd; $p=0.014$ ), of glycopeptides (PRÉ $=289$ DOT / 1000pd vs POST $=216$ DOT / 1000pd; $p=0.043$ ) and polymyxin B $(P R E=141$ DOT $/ 1000 p d$ vs POST $=92$ DOT $/ 1000 p d ; p=0.032)$ with increased exposure to penicillins $(\mathrm{PRE}=26$ DOT $/$ 1000pd vs POST = 51 DOT / 1000pd; $p=0.043)($ Table 2$)$.

The diagnostic indications for the use of antimicrobials, in each unit reflecting in the combined ICUs, were predominantly related to respiratory infections and septic shock. The only difference observed after intervention was the reduction in indications for surgical site infections in ICU 2 (PRE $=4.3 \%$ vs POST = $1.4 \% ; p=0.032$ ) (Table 3). 
Table 3

Diagnostic indications, per unit, 2019.

\begin{tabular}{|c|c|c|c|c|c|c|c|c|c|}
\hline \multirow{3}{*}{$\begin{array}{l}\text { DIAGNOSTIC } \\
\text { INDICATIONS (\%) }\end{array}$} & \multicolumn{9}{|c|}{ UNITS } \\
\hline & \multicolumn{3}{|c|}{ GLOBAL } & \multicolumn{3}{|l|}{ ICU 1} & \multicolumn{3}{|l|}{ ICU 2} \\
\hline & PRE & POST & $\begin{array}{l}\mathrm{p}- \\
\text { value }\end{array}$ & PRE & POST & $\begin{array}{l}\mathrm{p}- \\
\text { value }\end{array}$ & PRE & POST & p-value \\
\hline $\begin{array}{l}\text { Respiratory } \\
\text { infection }\end{array}$ & 37.4 & 32.8 & $\otimes 0.140$ & 37.0 & 29.7 & $\otimes 0.103$ & 37.7 & 36.4 & $\llbracket 0.744$ \\
\hline Septic shock & 14.4 & 14.6 & $\otimes 0.814$ & 17.0 & 13.6 & $\otimes 0.431$ & 12.2 & 15.7 & $\varangle 0.494$ \\
\hline $\begin{array}{l}\text { Sepsis pulmonary } \\
\text { focus }\end{array}$ & 7.2 & 8.8 & $\varangle 0.501$ & 8.3 & 11.6 & $\otimes 0.328$ & 6.2 & 5.5 & $\llbracket 0.754$ \\
\hline $\begin{array}{l}\text { PBCl-CVC with } \\
\text { Culture }(+)\end{array}$ & 5.3 & 9.5 & $\otimes 0.185$ & 4.1 & 8.5 & $\otimes 0.345$ & 6.3 & 10.6 & $\otimes 0.326$ \\
\hline Urinary infection & 6.2 & 8.3 & $\otimes 0.312$ & 3.3 & 8.9 & $\otimes 0.055$ & 8.7 & 7.5 & $\varangle 0.748$ \\
\hline Clinical sepsis & 6.0 & 7.8 & $\otimes 0.410$ & 5.9 & 7.3 & $\otimes 0.581$ & 6.2 & 8.4 & $\varangle 0.436$ \\
\hline $\begin{array}{l}\text { Surgical } \\
\text { prophylactic }\end{array}$ & 6.9 & 5.7 & $\otimes 0.147$ & 8.6 & 7.3 & $\otimes 0.226$ & 5.4 & 3.7 & $\varangle 0.320$ \\
\hline $\begin{array}{l}\text { Infection of the } \\
\text { surgical site }\end{array}$ & 3.8 & 2.5 & $\otimes 0.154$ & 3.1 & 3.4 & $\otimes 0.874$ & 4.3 & 1.4 & $\otimes 0.032^{\star}$ \\
\hline $\begin{array}{l}\text { Sepsis abdominal } \\
\text { focus }\end{array}$ & 2.6 & 2.7 & $\otimes 0.959$ & 1.4 & 3.4 & $\otimes 0.345$ & 3.7 & 1.9 & $\varangle 0.463$ \\
\hline $\begin{array}{l}\text { Skin / soft tissue } \\
\text { infection }\end{array}$ & 2.9 & 2.3 & $\varangle 0.438$ & 3.0 & 2.0 & $₫ 0.554$ & 2.8 & 2.6 & $\bowtie 0.880$ \\
\hline $\begin{array}{l}\text { Sepsis urinary } \\
\text { focus }\end{array}$ & 2.3 & 2.1 & $\otimes 0.838$ & 1.2 & 2.0 & $\otimes 0.215$ & 3.3 & 2.3 & $\otimes 0.476$ \\
\hline $\begin{array}{l}\text { Skin / soft tissue } \\
\text { sepsis }\end{array}$ & 2.0 & 1.1 & $\otimes 0.109$ & 4.1 & 0.8 & $\otimes 0.080$ & 0.2 & 1.4 & $\bowtie 0.465$ \\
\hline $\begin{array}{l}\text { Central nervous } \\
\text { system infection }\end{array}$ & 1.8 & 0.5 & $\otimes 0.249$ & 2.4 & 0.9 & $\otimes 0.225$ & 1.3 & 0 & $\otimes 0.109$ \\
\hline $\begin{array}{l}\text { Abdominal } \\
\text { infection }\end{array}$ & 0.6 & 1.4 & $\varangle 0.245$ & 0.3 & 0.5 & $\otimes 0.317$ & 0.9 & 2.5 & $\llbracket 0.228$ \\
\hline
\end{tabular}

Regarding clinical outcomes, in the combined ICUs, reductions in the incidence of resistance to Methicillin ${ }^{R}$, Vancomycin ${ }^{R}$, A. Carbapenem ${ }^{R}$, and E. Carbapenem ${ }^{R}$ were observed, although not significant. There was no significant difference in the length of hospital stay and the overall mortality rate of patients $(p>$ 0.005) (Table 4). 
Table 4

Clinical Outcomes, per unit, 2019.

\begin{tabular}{|c|c|c|c|c|c|c|c|c|c|}
\hline \multirow{3}{*}{$\begin{array}{l}\text { CLINICAL } \\
\text { OUTCOMES }\end{array}$} & \multicolumn{9}{|c|}{ UNITS } \\
\hline & \multicolumn{3}{|c|}{ GLOBAL } & \multicolumn{3}{|l|}{ ICU 1} & \multicolumn{3}{|l|}{ ICU 2} \\
\hline & PRE & POST & $\begin{array}{l}\mathrm{p}- \\
\text { value }\end{array}$ & PRE & POST & $\begin{array}{l}\text { p- } \\
\text { value }\end{array}$ & PRE & POST & $\begin{array}{l}\mathrm{p} \text { - } \\
\text { value }\end{array}$ \\
\hline \multicolumn{10}{|l|}{ Resistance } \\
\hline Methicillin ${ }^{R}$ & 66.2 & 51.8 & $\triangle 0.433$ & 50.0 & 50.0 & $\nabla 1.000$ & 54.2 & 33.1 & $\nabla 0.406$ \\
\hline Vancomycin ${ }^{\mathrm{R}}$ & 40.0 & 12.5 & $₫ 0.273$ & 16.7 & 16.7 & $\nabla 1.000$ & 30.6 & 11.1 & $\nabla 0.285$ \\
\hline P. Carbapenem ${ }^{R}$ & 48.9 & 57.5 & $\triangle 0.655$ & 54.2 & 54.9 & $\otimes 0.970$ & 43.1 & 56.7 & $\otimes 0.645$ \\
\hline A. Carbapenem ${ }^{R}$ & 92.7 & 92.5 & $\nabla 1.000$ & 83.3 & 96.3 & $\otimes 1.000$ & 94.3 & 85.0 & $\nabla 0.285$ \\
\hline E. Carbapenem ${ }^{R}$ & 40.5 & 29.4 & $\triangle 0.386$ & 46.7 & 9.0 & $\nabla 0.045^{\star}$ & 27.8 & 41.6 & $\otimes 0.466$ \\
\hline Time of stay & 14 & 14 & $\$ 1.000$ & 14 & 14 & $\otimes 0.576$ & 14 & 14 & $\otimes 0.646$ \\
\hline $\begin{array}{l}\text { Overall mortality } \\
\text { (\%) }\end{array}$ & 24.4 & 25.6 & $\otimes 0.551$ & 25.4 & 23.6 & 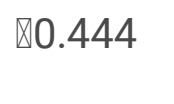 & 23.0 & 27.8 & $\otimes 0.162$ \\
\hline
\end{tabular}

Methicillin ${ }^{\mathrm{R}}$ - Methicillin-resistant Staphylococcus aureus; Vancomycin ${ }^{\mathrm{R}}$ - Vancomycin-resistant enterococci; P. Carbapenem ${ }^{R}$ - Carbapenem-resistant Pseudomonas aeruginosa; A. Carbapenem ${ }^{R}$ Carbapenem-resistant Acinetobacter baumannii; E. Carbapenem ${ }^{\mathrm{R}}$ - Carbapenem-resistant Enterobacteriaceae

$\otimes$ Student's $t$ test, $\otimes$ Wilcoxon rank-sum tests, ${ }^{*} p$-value $<0.05$

\section{Discussion}

The data exposed in this study demonstrate that, in the combined ICUs, in the pre-intervention period, $91.4 \%$ of the patients received at least one antimicrobial agent and, although not significant, there was a slight reduction in the post-intervention period to $90.0 \%$. De Bus L et al. [3], when conducting a study for four years in an ICU at the University Hospital in Ghent, observed that $84 \%$ of patients, with a stay $>48 \mathrm{~h}$, were exposed to at least one class of antibiotics. Álvarez-Lerma F et al. [11], when evaluating this data in an ICU of a general hospital in Barcelona, reports that in the year before the intervention $77.8 \%$ of the patients received one or more antimicrobials, and in the following year, after the intervention, there was a reduction to $71.4 \%$. At a London University Hospital, Candeloro CL et al. [1], over a study period of 30 days, found that $73 \%$ of patients, with a stay $>24 \mathrm{~h}$, were exposed to some antimicrobial. In contrast, 
lower percentages were reported in ICUs in hospitals in the United States and Europe that had $57 \%$ of patients using antimicrobials [4].

One of the main factors that lead to the extensive use of antimicrobials in intensive care units is associated with the severity of patients, a condition that, in most cases, requires the early start of antibiotics, due to the greater probability of contracting infections, representing about $20 \%$ of total hospital infections. These infected patients have an even higher risk of mortality $[2,4,5]$. These differences found in the literature may be related to the type of care provided in the intensive care units of each hospital. In the present study, the high percentage of the use of antimicrobials portrays the predominant admission of highly complex and polytrauma patients.

The parenteral route was, in general, the main choice for the administration of antimicrobials, corroborating with the data found in the literature $[1,6]$. Candeloro $C L$ et al. [1] reports that among $90 \%$ of prescriptions directed to the parenteral route, only $5.8 \%$ were transferred to the enteral route. After the intervention, reductions in the indication of these pathways, although not significant, were observed in the combined ICUs linked to reductions in the ICU 1. The predilection of the parenteral route may be related, among others, to the necessary immediacy of the results, also, the options for the oral route are limited. The switch from parenteral to enteral in ICUs is a very controversial subject. Changing the route may bring some important results, such as early discharge, less risk of bacteremia, less use of venous access, and incidence of thrombophlebitis, and lower cost of treatment [12].

The most prescribed antimicrobial classes with the longest exposure time were related to carbapenems, followed by glycopeptides, reflecting the main diagnostic indications observed in this study, which refer to respiratory infections and septic shock. In addition to the antimicrobials described, studies still show expressive values of cephalosporin prescriptions in intensive care units $[1-3,6-8,12]$. These findings corroborate with several studies that point out respiratory infections, followed by urinary infections, which explains the emphasis on cephalosporins, as the main predictors for the use of antimicrobials in ICUs [2$4,12]$.

The data reveal that the most recurrent antimicrobial therapy involves agents of a broad spectrum and that it is often performed empirically, during the uncertainty of the diagnosis, not always representing the appropriate therapy [2,4]. That is why it is important to send cultures before starting antimicrobials, making it possible to verify the response to treatment more quickly. Empirical therapy should be guided by accurate and recent antibiograms, in addition to having standardized approaches that take into account the susceptibility pattern of bacteria commonly isolated in the units [4].

The mean duration of antimicrobial therapy was 703 LOT / 1000pd, with a significant reduction in the combined ICUs. In Brazil, Marcelino FAB [2], found a rate slightly above the finding (median = 844 LOT / $1000 \mathrm{pd})$. These high rates reflect the complexity of infections acquired by patients in intensive care units. Also, the age group of the population observed, in this study requires a longer time for recovery, enabling the acquisition of secondary infections. Each patient received an average of $1.8 \pm 0.2$ antimicrobials during their stay in the units, indicating that the combination of antimicrobial therapy is common in 
hospital ICUs. There was a significant reduction in this data when observed in the combined ICUs, linked to a reduction in the number of antimicrobials prescribed in the ICU2.

In the combined ICUs, significant increases were observed in the exposure time of penicillins and tigecycline, with marked reductions in the time of use of glycopeptides and polymyxin B. When comparing the pre-and post-intervention periods, individually in the units, it was found that, in ICU 1, there was a significant increase in the exposure time for penicillins and tigecycline. While in ICU 2, a notable increase was found for the exposure time of penicillin, with a reduction in the time of use of carbapenems, glycopeptides, and polymyxin B. The results of this study are consistent with the findings by Hwang $\mathrm{H}$ [9] when evaluating the impact of interventions led by specialists in infectious diseases in the use of antibiotics in a large Korean hospital.

It appears that the use of antimicrobials against multi-resistant microorganisms was significantly affected by the intervention of specialists. Vancomycin continues to be used as a first-line treatment for serious infections caused by multidrug-resistant staphylococci. However, a reduction in multiple-resistant Staphylococcus aureus (MRSA) susceptibility, as well as resistance to vancomycin has been reported recently in many countries. On the other hand, tigecycline provides an alternative treatment for infections complicated by MRSA, vancomycin-resistant enterococci, in addition to other multiple drug resistance microorganism isolates $[13,14]$. When increasing the use of penicillins, mainly represented by piperacillintazobactam, it can be explained as an effective strategy as an alternative to the use of carbapenems in the treatment of infections of low to moderate severity, originated from urinary or biliary sources, caused by extended-spectrum beta-lactamase-producing Enterobacteriaceae [15].

The median length of stay, overall, in the units, was 14 days. The literature describes, for intensive care units, one remained ranging from 6 to 18 days $[2,7,11,12]$. These observed variations can be explained due to the characteristics of the patients seen at each institution. Although intervention in the present study slightly decreased the use of antimicrobials, there were no changes in the length of stay and survival of patients.

The strengths of this study include the prospective design with comparison before and after interventions of a team of infectious diseases specialist in the rationalization of the use of antimicrobials in intensive care units, the direct investigation of the prescriptions enabling a greater precision of the analysis regarding the use of antimicrobials and the use of the DOT and LOT indicators according to the new recommendations for monitoring the use of antimicrobials. However, some limitations were noted: First, the study was conducted at a single center. Second, comorbidities have not been evaluated. Third, the adequacy of the prescriptions was not addressed. Fourth, no data were obtained on the prevalence of bacterial pathogens and their susceptibility patterns.

\section{Conclusion}

In general, the intervention of infectious diseases specialists in intensive care units had a limited impact on the results evaluated. This may be due to the short period analyzed. Although the difference in the 
percentage of patients using antimicrobials, after the intervention, was not significant, a small drop in data was observed, significantly interfering with the time of exposure to certain broad-spectrum agents, which may have influenced, even though not significant, in the fall in the incidence of microbial resistance for some antibiotics. Therefore, it is important to monitor the impact of these changes in the long term, drawing a more accurate assessment of the effectiveness of an intervention, with the implementation of active feedback.

The hospital does not have a management program for the use of antimicrobials, nor does it have a basic structure or adequate resources for its development, but these initiatives, although immature, can gradually interfere significantly in the care of patients.

\section{Abbreviations}

\section{A. Carbapenem ${ }^{R}$ - Carbapenem-resistant Acinetobacter baumannii}

DOT - Days of Therapy

E. Carbapenem ${ }^{\mathrm{R}}$ - Carbapenem-resistant Enterobacteriaceae

ICU - Intensive Care Unit

LOT - Length of Therapy

Methicillin ${ }^{\mathrm{R}}$ - Methicillin-resistant Staphylococcus aureus

MRSA - Multiple-resistant Staphylococcus aureus

P. Carbapenem ${ }^{\mathrm{R}}$ - Carbapenem-resistant Pseudomonas aeruginosa

PD - Patient-days

Vancomycin ${ }^{\mathrm{R}}$ - Vancomycin-resistant enterococci

\section{Declarations}

Ethics approval and consent to participate. This study was approved by the Research Ethics Committee of the Federal University of Sergipe, with CAAE: 15583219.4.0000.5546, under opinion No. 3.518.197 and by the Institutional Teaching and Research Center. A waiver of informed consent was obtained due to the non-interventional nature of this study and the complete anonymity of patient data.

Consent for publication. Not applicable.

Availability of data and materials. All data generated or analyzed during this study are included in this published article [and its supplementary information files]. 
Competing interests. The authors declare that they have no competing interests.

Funding. Coordination for the Improvement of Higher Education Personnel (CIHEP)

Authors' contributions. RMRS collected, analyzed, and interpreted the data and wrote the work. ACBC, EKCVK, WBS, and IMFL contributed to the conception of the work and substantially revised it. All authors read and approved the final manuscript.

Acknowledgments. To all members of the Center for Epidemiology, Patient Safety and Hospital Infection (CEPSHI).

\section{References}

1. Candeloro CL, Kelly LM, Bohdanowicz E, Martin CM, Bombassaro AM. Antimicrobial use in a critical care unit: A prospective observational study. Int J Pharm Pract. 2012. doi:10.1111/j.20427174.2011.00176.x.

2. Marcelino FAB. Uso de antimicrobianos em unidades de terapia intensiva pediátrica e adulta de um hospital público terciário. 2013. Dissertação (Mestrado em Ciências da Saúde) - Programa de PósGraduação em Ciências da Saúde, Universidade Federal de Sergipe, 2013.

3. De Bus L, Gadeyne B, Steen J, Boelens J, Claeys G, Benoit D, De Waele J, Decruyenaere J, Depuydt. P. A complete and multifaceted overview of antibiotic use and infection diagnosis in the intensive care unit: results from a prospective four-year registration. Crit Care. 2018. doi:10.1186/s13054-018-21787.

4. Nathwani D, editor. Antimicrobial stewardship: from principles to practice. British Society for Antimicrobial Chemotherapy. http://www.bsac.org.uk/antimicrobialstewardshipebook/BSACAntimicrobialStewardship-FromPrinciplestoPractice-eBook.pdf. Published 2018.

5. Feitosa TS, Assis RAS, Coêlho ML. Utilidade de indicadores para o monitoramento do consumo de antimicrobianos de uso restrito em uma unidade de terapia intensiva. Jornal de Ciências Da Saúde Do Hospital Universitário Da Universidade Federal Do Piauí. 2018; doi:10.26694/25950290.20181242-506963.

6. Balkhy HH, El-Saed A, El-Metwally A, Arabi YM, Aljohany SM, Al Zaibag M, Baharoon S, Alothman AF. Antimicrobial consumption in five adult intensive care units: a 33-month surveillance study. Antimicrobial Resistance Infection Control. 2018. doi:10.1186/s13756-018-0451-9.

7. Rupali P, Palanikumar P, Shanthamurthy D, Peter JV, Kandasamy S, Zacchaeus NGP, Alexander H, Thangavelu P, Karthik R, Abraham OC, Michael JS, Paul H, Veeraraghavan B, Chacko B, Jeyaseelan V, Alangaden G, Prentiss T, Zervos MJ. Impact of an antimicrobial stewardship intervention in india: evaluation of post-prescription review and feedback as a method of promoting optimal antimicrobial use in the intensive care units of a tertiary-care hospital. In Infection Control Hospital Epidemiology. 2019. doi:10.1017/ice.2019.29. 
8. Ribeiro MC, Calvacate GL, Batista MKP, Côelho ML, Carvalho CGN. Indicadores

farmacoepidemiológicos do uso de antimicrobianos de amplo espectro em um hospital privado. Revista Interdisciplinar de Ciências Médicas.

9. Hwang H, Kim B. Impact of an infectious diseases specialist-led antimicrobial stewardship programmes on antibiotic use and antimicrobial resistance in a large Korean hospital. Sci Rep. 2018. doi:10.1038/s41598-018-33201-8.

10. Public Health Ontario. Ontario. Antimicrobial Stewardship Programs. Metrics Examples. Toronto, ON: Queen's Printer for Ontario. https://www.publichealthontario.ca/en/eRepository/ASP_Metrics_Examples.pdf. Published 2017.

11. Álvarez-Lerma F, Grau S, Echeverría-Esnal D, Martínez-Alonso M, Gracia-Arnillas MP, Horcajada JP, Masclansa JR. A before-and-after study of the effectiveness of an antimicrobial stewardship program in critical care. Antimicrob Agents Chemother. 2018. doi:10.1128/AAC.01825-17.

12. Gasparetto J, Tuon FF, Oliveira DS, Zequinao T, Pipolo GR, Ribeiro GV, Benincá PD, Cruz JAW, Moraes TP. Intravenous-to-oral antibiotic switch therapy: A cross-sectional study in critical care units. BMC Infect Dis. 2019. doi:10.1186/s12879-019-4280-0.

13. Kresken M, Körber-Irrgang B, Petrik C, Seifert H, Rodloff A, Becker K. Temporal trends of the in vitro activity of tigecycline and comparator antibiotics against clinical aerobic bacterial isolates collected in Germany, 2006-2014: results of the Tigecycline Evaluation and Surveillance Trial (TEST). GMS Infect Dis. 2016. doi:10.3205/id000025.

14. Shariati A, Dadashi M, Chegini Z, van Belkum A, Mirzaii M, Khoramrooz SS, Darban-Sarokhalil D. The global prevalence of Daptomycin, Tigecycline, Quinupristin/Dalfopristin, and Linezolid-resistant Staphylococcus aureus and coagulase-negative staphylococci strains: a systematic review and meta-analysis. Antimicrob Resist Infect Control. 2020. doi:10.1186/s13756-020-00714-9.

15. Karaiskos I, Giamarellou H. Carbapenem-Sparing Strategies for ESBL Producers: When and How. Antibiotics (Basel). 2020. doi:10.3390/antibiotics9020061. 